\title{
UM CONVITE PARA REPENSAR A IGNORÂACIA: \\ SOBRE O EXERCÍCIO DA FUNÇÃO-ORIENTADOR
}

André Bocchetti ${ }^{\mathrm{i}}$

José Claudio Sooma Silvaii

\begin{abstract}
Resumo: $\mathrm{O}$ artigo concentra o foco em dois principais tensionamentos que parecem um tanto especiais para compreender o exercício da função-orientador nas instituições universitárias. O primeiro diz respeito ao modo como pensamos a forma escolar; o segundo se refere à maneira como vislumbramos os lugares do texto e da escrita na relação acadêmica. Tal percurso investigativo foi estimulado pelo desejo de encontrar itinerâncias entre Michel Foucault e a Educação que, de algum modo, nos desafiem a (re)pensar aquilo que cotidianamente fazemos (ou deixamos de fazer) em nossos exercícios docentes na contemporaneidade.
\end{abstract}

Palavras-chave: Michel Foucault, Função-Orientador, Escrita de Si, História da Educação.

\begin{abstract}
The article focuses on two main aspects specials to understanding the role of function-advisor in university institutions. The first relates to the way we think about the school form; the second refers to the way we understand the places of text and writing in the university. Such study was stimulated by the desire to find itineraries between Michel Foucault and Education that, in some way, challenge us to (re)think what we daily do (or fail to do) in our teaching practice today.
\end{abstract}

Keywords: Michel Foucault, Function-advisor, Self-writing, History of Education. 


\section{Introdução}

Diziam nossos professores de matemática, já faz algum tempo, que função é aquilo que coloca os conjuntos em relação. Gilles Deleuze e Félix Guattari (1992), por sinal, se atreveram a afirmar que essa era justamente a característica fundamental da própria ciência: produzir relações entre diferentes entes, expressas em fórmulas físicas ou em organizações biológicas, é o que dá sentido a muitos dos esforços daquilo que a modernidade escolheu chamar de "desenvolvimento científico". Mas, o que talvez tenhamos atentado com mais cuidado somente a partir de autores como Michel Foucault é que os elementos functivos, ao colocarem em relação, individualizam, já que toda função opera dentro de um plano discursivo tentando livrar a linguagem e a enunciação do próprio caos. Pôr em relação, já há muito, é inaugurar entes, dar-lhes certos limites e contornos, justamente, pelo exercício de separação subjacente a qualquer enunciado relativo.

Veja-se, exemplarmente, as discussões de Foucault sobre a função-autor. Em seu belo e conhecido texto “O que é um autor?” (1992), ele indicia o lugar operacional do conceito de autoria sobre os discursos com o qual tal conceituação se relaciona. A noção de autor reorganiza enunciados, lhes define ora propriedade, ora classificação, ora agrupamentos, ora recusas. O autor é uma função discursiva fundamental; condição sine qua non, por sinal, para que a própria individualidade moderna pudesse se consolidar (LE BRETON, 2016).

Queremos, aqui, de maneira exploratória, nos debruçar sobre alguns elementos de uma outra função discursiva que, embora não se mostre tão fundamental ao discurso moderno como aquela enunciada por Foucault, nos parece ter uma grande relevância à produção dos modos pelos quais nos relacionamos hoje no ambiente acadêmico: a função-orientador. De modo assemelhado àquilo que acontece com a noção de autoria, é provável que a figura da orientação traga, em seu funcionamento discursivo, um número imenso de possibilidades operacionais historicamente constituídas - pensemos, por exemplo, nas diferenças entre a ação orientadora nos tempos em que a figura do professor catedrático estava ainda fortemente estabelecida na estrutura universitária e nos dias de hoje. De qualquer modo, uma análise como essa exigiria um esforço genealógico que foge aos limites e recortes deste artigo. Por isso mesmo, interessou-nos concentrar as atenções em dois tensionamentos que parecem um tanto especiais para compreender a função-orientador em alguns de seus pressupostos atuais. Um deles diz respeito ao modo como pensamos a forma escolar; o outro, à maneira como vislumbramos os lugares do texto e da escrita na relação acadêmica. Exercícios analíticos alimentados pelo desejo de encontrar itinerâncias entre Michel Foucault e a Educação que animam este dossiê, e que nos desafiam e convidam, portanto, a refletir sobre a função-orientador no bojo daquilo que cotidianamente fazemos (ou deixamos de fazer) em nossos exercícios docentes. 
$\mathrm{Na}$ medida em que nos voltamos àquilo que fazemos nos dias de hoje como professoresorientadores, torna-se oportuno, antes de tudo, realçar dois aspectos que se encontram entrelaçados na carreira docente universitária. Para tanto, relembramos determinadas exigências que os responsáveis pelo exercício docente tiveram que percorrer. Em seguida, cumpre recordar algumas das atividades que somos convidados (ou impelidos) a desenvolver dentro das atribuições e responsabilidades de nossa atuação institucional.

Sobre as exigências requeridas por aqueles que almejam pleitear o ingresso na carreira docente, sublinhamos que diferentemente de outras modalidades de concurso público ${ }^{\mathrm{iii}}$, para que se torne possível concorrer à vaga de professor universitário é necessária uma trajetória anterior que leva, em média, 10 anos (4 de graduação, 2 de mestrado e 4 de doutorado) - salvo algumas exceções onde se pode ingressar com o diploma da graduação (professor auxiliar) ou de mestrado (professor assistente) e/ou alguns programas onde o curso de mestrado estende-se por $3 \operatorname{anos}^{\mathrm{iv}}$.

Acerca disso, cumpre realçar que essa trajetória de 10 anos, em média, é caracterizada por um repertório de disciplinas cursadas (obrigatórias e eletivas); textos lidos, fichados e debatidos; provas, seminários, trabalhos finais; exames de projeto, de qualificação; defesas públicas de monografias de conclusão de curso de graduação, dissertações de mestrado e teses de doutorado. Ainda assim, finalizada esta jornada, nada assegura que será alcançado o ingresso na carreira docente superior, posto que há a necessidade de abertura de vagas, aprovação em uma nova bateria de exames (prova escrita, prova de aula, arguição de memorial acadêmico à vista do currículo etc.).

No que tange às atribuições e responsabilidades que devem ser desempenhadas pelos professores universitários, registramos que as considerações a seguir encontram-se ancoradas na Resolução no. 8/2014 do Conselho Universitário da UFRJ que "Estabelece normas e critérios para o desenvolvimento na Carreira de Magistério Federal'. Este documento, aprovado em novembro de 2014, enfatiza o regime de dedicação exclusiva e estipula aquelas incumbências que precisam ser executadas pelos professores universitários no decurso de suas trajetórias profissionais. São divididas em cinco categorias que, esquematicamente, podem ser sistematizadas da seguinte forma:

1) Docência (aulas na graduação e na pós-graduação; orientações de alunos; participação de bancas de avaliação de graduação, mestrado e doutorado; supervisão de pós-doutorado etc.);

2) Pesquisa e Produção Intelectual (publicação de artigos, livros, capítulos de livros; palestras; conferências; participação em congressos, simpósios e demais eventos; coordenação de projetos de pesquisa etc.);

3) Extensão (cursos; oficinas; palestras; editoração de revistas; organização de eventos; entrevistas; estreitamento de laços da Universidade com a comunidade; orientação de alunos em projetos de extensão etc.); 
4) Atividades de Gestão Administrativa e de Representação (cargos de chefias de departamento, administração superior na Universidade, conselhos superiores, coordenações de estágios, monitorias; diretorias etc.);

5) Qualificação Acadêmico-Profissional (pós-doutorado; membro de comitês editoriais; consultorias para agências de fomento à pesquisa; participação em bancas de concursos públicos; prêmios e distinções conquistados etc.).

Num quadro geral, essas são as obrigações exigidas para o ingresso e as atribuições e responsabilidades requeridas para o exercício docente no ensino superior público no Brasil ${ }^{\mathrm{v}}$. Destacá-las, neste momento, constituiu-se como uma estratégia escriturária interessada em preparar o terreno para que tenhamos a ocasião de aventar a possibilidade de fazer emergir outras experiências de formação e de construção do conhecimento que ultrapassem aquilo que é o ansiado e demandado, institucionalmente, em nossas atuações docentes. Os próximos tópicos versarão sobre a tentativa de nos aproximarmos de algumas dessas outras experiências.

\section{Joseph Jacotot: notas para pensar as experiências modificadoras e a forma escolar}

De partida, relembramos a aventura intelectual narrada por Jacques Rancière no seu Mestre Ignorante (2010). No início do século XIX (1818) um professor francês - Joseph Jacotot - que não sabia palavra alguma da língua holandesa se vê diante do desafio de ensinar para uma turma de holandeses que não sabia nada da língua francesa. Aquilo que à primeira vista seria um empreendimento fadado ao fracasso, converte-se num estimulante experimento com resultados surpreendentes: a turma e o professor começam a se entender, se familiarizar e, fundamentalmente, a construir relações de aprendizagem. Diante do inusitado da situação, o professor decide aprofundar essa primeira experiência e, de propósito, se oferece para ministrar outras duas disciplinas: piano e pintura.

O Mestre Ignorante de Rancière (2010) se apresenta, em primeiro plano, como uma crítica contundente àquilo que o autor denominou de ordem explicadora que caracterizaria a relação mestres/alunos. Esta ordem explicadora se alicerça, particularmente, no desnivelamento dos primeiros sobre os segundos: os mestres "sabem" e, por meio de dispositivos didáticos explicariam para os que desconhecem. Pressupostos, portanto, dessa relação: a hierarquia, a desigualdade e o distanciamento.

No lugar desse desnivelamento, Rancière defende que a experiência é o que confere (ou deveria conferir) sentido à educação. Afinal, muito mais importante do que "ensinar" o que já sabemos, se configura aquele empreendimento preocupado em aprender e nos transformarmos com aquilo que pode (ou deve!) ser apreendido em um exercício que tencione, de algum modo, produzir conhecimento. Sobre esse aspecto, a experiência estabelece articulações com uma escrita de si (e de nós) que necessita abrir espaços para as 
falhas, os imprevistos, as hesitações e, sobretudo, para os erros que se constituem como elementos integrantes e imprescindíveis para todo e qualquer exercício de aprendizagem (FOUCAULT, 2010). Nessa medida, que saiamos (mestres e aprendizes) diferentes e modificados em relação às formas que entramos nas variadas experiências educativas: este é o convite e, num certo sentido, o desafio.

Após essa primeira incursão acerca daquilo que é explorado no Mestre Ignorante, chegamos àquela questão que gostaríamos de sublinhar e que se imbrica às reflexões de Rancière (2010). Como foi enfatizado, no decurso de nossa trajetória de estudantes (graduação, mestrado, doutorado) vivenciamos as mais variadas circunstâncias de formação que procuram apresentar, explorar, discutir aspectos referentes à profissão, áreas de atuação, problemáticas de pesquisa etc. Por outro lado, dentre as atribuições e responsabilidades que devem ser desempenhadas pelos professores universitários, as orientações de trabalhos de monografia de conclusão de curso de graduação, dissertações de mestrado e teses de doutorado têm ocupado, cada vez mais, espaços nas nossas agendas de tarefas e compromissos.

No entanto, se pararmos para refletir, não existiu (e permanece não existindo) "cadeira", ou disciplina, ou prova, ou concurso, ou avaliação - ou qualquer coisa do gênero - que apresentou, sistematizou, sublinhou, ou seja, nos ensinou a ser "orientadores". Acerca desses aspectos, as lembranças de nossas primeiras experiências formativas na graduação, no mestrado e, mesmo, no doutorado são sugestivas, enquanto indícios, de como já estivemos (des)orientados algum dia, ou quase isto.

É em função desse quadro de considerações que parece assumir pertinência uma ponderação de fundo, que concebemos como de especial importância para (re)pensar algumas dimensões de nossa atuação docente na contemporaneidade. No caso, a referência é para a questão de que o exercício da funçãoorientador alude para todo um repertório de circunstâncias, experiências e possibilidades que emergem a partir de aspectos outros que não, exclusivamente, aqueles referentes à forma escolar de produção de conhecimentos (VINCENT; LAHIRE; THIN 2001). Nessa medida, concentrar as atenções em algumas das características do exercício da função-orientador sinaliza, também, para um movimento interessado em trazer à tona os diferentes modos de aprendizagem que, a contar principalmente dos tempos modernos, foram sendo subsumidos para o fortalecimento da forma escolar (VILLELA, 2007, p. 97).

Não se trata, neste momento, de mergulhar no fenômeno da escolarização, realçando a organização, institucionalização e difusão de uma forma de socialização, cujas influências se encontram "muito além dos muros da escola" (FARIA FILHO; VAGO, 2009, p. 6). Tampouco de revistar todo um conjunto de pesquisas ${ }^{\text {vi }}$ que investigou as decisivas contribuições da educação, como um todo, e da escola, em particular, para "o processo civilizador das sociedades ocidentais que, basicamente a partir do século 16, desenvolveu parâmetros de racionalização dos gestos e das condutas, com o fito de estabelecer redes, elos, cadeias sociais, voltados para civilizar comportamentos" (BOTO, 2014, p. 102). 
No lugar disso, estabelecemos essa interlocução com a literatura voltada para a temática com o anseio de enfatizar que a consolidação da forma escolar, dentre outras dimensões, concorreu para atenuar a importância das práticas e experiências como disparadoras de aprendizagens diversas. A esse respeito, torna-se operacional pontuar, por exemplo, que por bastante tempo os próprios ensinamentos da leitura, escrita e contas aos meninos e meninas ficavam sob responsabilidade dos "mestres e artesãos das corporações de ofícios especializados, como os carpinteiros, os ferreiros, os alfaiates, entre outros" (SCHUELER, 2007, p. 70). Nessa direção, prossegue a autora:

A própria denominação - mestre - então atribuída aos docentes de todas as ordens e graus, indicava a sua vinculação com as tradições das corporações de ofício [...]. Tendo aprendido com os mestres no interior dos sistemas de aprendizagem de ofícios, alguns artesãos ao mesmo tempo em que exerciam suas profissões manuais, executavam a tarefa de ensinar as primeiras letras (SCHUELER, 2007, p. 70).

Frente a essas considerações, ao aludir a consolidação da forma escolar - movimento que trouxe consigo um conjunto de sistematizações, prescrições, controles e fiscalizações que tencionavam harmonizar, disciplinar e organizar as variadas práticas difusas de educação - pretendemos enfatizar o imprescindível estranhamento que deve anteceder, acompanhar e permanecer no horizonte de preocupações daqueles que se propõem a investigar o campo da Educação. Afinal, a forma escolar não foi (e nunca será) "natural”. Tanto assim que, não por acaso, foi a partir do final do século XVIII e início do XIX que, sob a lógica do governo das populações, o dispositivo da obrigatoriedade escolar (acompanhado de multas pecuniárias e sanções diversas para aqueles que não matriculassem seus filhos) passa a ser, cada vez mais, acionado: entre 1763 e 1803, Prússia, Áustria, Saxônia e Baviera foram os primeiros estados nacionais a introduzir a obrigatoriedade escolar (DUSSEL; CARUSO, 2003, p. 109). À guisa de informação, no caso do Rio de Janeiro, a obrigatoriedade escolar assume contornos na Província, em 1849, e é legalmente instituída na Corte Imperial em 1854 (SCHUELER; SILVA, 2013) vii .

É mesmo significativo perspectivar determinadas dimensões da forma escolar mergulhados na aventura intelectual narrada por Rancière (2010). Isso porque a aludida ordem explicadora que caracteriza a relação professores/alunos que se baseia, fundamentalmente, no desnivelamento (os professores sabem e os alunos não!) atravessa, embaralha e interfere muitas das circunstâncias presentes no cotidiano das escolas. Destaca-se, nesta direção, inclusive a apropriação que tem sido feita da categoria de análise de liturgia para problematizar o fenômeno da escolarização em função de seus tempos, espaços, conteúdos, rituais, rotinas, frequência, ciclos, avaliações, promoções, reprovações, usos, costumes, hierarquias etc. Algo, portanto, que nos convida a refletir sobre "uma maneira de ser escola, que se expressa mediante rituais, mobilizando sentimentos, experiências e símbolos" (BOTO, 2014, p. 102). Mas, no caso do 
exercício da função-orientador, essa ordem explicadora assume, ao lado deste desnivelamento, outros contornos e colorações que serão explorados a seguir.

\section{Ainda acompanhados por Jacotot, mas, também, por Foucault: um guia possível à orientação ignorante}

A ignorância do professor francês reencontrado por Rancière sustenta um processo educativo marcado pelo reconhecimento à igualdade das inteligências daqueles nele envolvidos. Isso só é possível a Jacotot na medida em que um elemento, colocado ao acaso em sua história (RANCIÈRE, 2010, p. 32), passa a operar, produzindo uma relação de partilha capaz de se afastar, como foi explorado no tópico anterior, de qualquer possibilidade de instauração de uma ordem explicadora. Junto com sua fragilidade potente do ignorar da língua, Jacotot se encontra com um livro: Telêmaco, de Fénelon; edição bilíngue, que materializa o laço mínimo do comum que se forma em torno das aulas do mestre francês.

Telêmaco é "uma fuga bloqueada: não se sabe que caminho traçará o aluno, mas sabe-se de onde ele não sairá - do exercício de sua liberdade" (RANCIÈRE, 2010, p. 35). A obra compartilhada instaura um "infinito" que já não está subsumido à figura explicadora do mestre, mas que se faz no encontro com o leitor-estudante. "Tudo está no livro" (RANCIÈRE, 2010, p. 35), e isto extirpa a possibilidade da incapacidade. Nessa medida, a relação com o texto, pelos caminhos diversos e nos signos que em sua descoberta emergem, impede que o aluno diga "eu não posso". A condição de incapaz não tem lugar frente à intempestividade acontecimental da leitura. Desde aí emerge algo por demais valioso nos ensinamentos de Jacotot a Rancière:

Há desigualdade nas manifestações da inteligência, segundo a energia mais ou menos grande que a vontade comunica à inteligência para descobrir e combinar relações novas, mas não há hierarquia de capacidade intelectual. É a tomada de consciência dessa igualdade de natureza que se chama emancipação, e que abre caminho para toda aventura no país do saber (RANCIERE, 2010, p. 38).

A igualdade emancipadora está, portanto, na potência realizadora do encontro comum com o texto. Está lá em Jacotot e seus estudantes, no século XIX, e talvez aqui, junto aos orientadores e orientandos em nossa contemporaneidade. Desta feita, parece possível pensar que a textualidade que anima a profícua relação de ignorância da personagem rememorada por Jacques Rancière pode, ainda que em outros termos, alimentar as relações centrais a uma função-orientador que escape à forma escolar de produção de conhecimento. Lá, como aqui, se trata de uma relação entre a leitura e a escrita - os alunos de Jacotot decoram, copiam, atuam com o texto. Nós e nossos orientandos, conquanto sejamos submetidos a um elenco 
de disciplinas (obrigatórias e eletivas) e ao cumprimento de um repertório de atividades que perfaça a carga horária estipulada pelos cursos de graduação e pós-graduação (mestrado e doutorado), ainda assim agimos sobre uma construção textual sempre presente e de algum modo submetida aos tensionamentos de nossos (des)encontros. Tanto é assim que, relembremos, são os textos finais das monografias de conclusão de curso de graduação, dissertações de mestrado e teses de doutoramento que, fundamentalmente, facultam as condições para que os rituais de encerramento conheçam os seus momentos de emersão: sem eles, não há como organizar uma banca de defesa/avaliação.

Mas há uma diferença importante. Os estudantes de Jacotot se encontram com um livro encerrado, e sua condição é aquela da leitura como operação subversiva de caça no espaço do outro, da qual nos fala Michel de Certeau (2008) ao sublinhar os atalhos empregados, os saltos promovidos, as apropriações transformadoras elaboradas, enfim, toda a sorte de atitudes, artes e artimanhas que colaboram para que pensemos as práticas de leitura, sobretudo, como produtoras de sentido para o que foi escrito. Nossos orientandos - ainda que convivam com as angústias relacionadas à inversão escriturária analisada por De Certeau (1982) que se faz presente, sem exageros, em toda e qualquer investigação: enquanto a pesquisa é infinita, a escrita já se inicia com a obrigação de ser finalizada - se deparam com as potencialidades e as dores por vezes ainda mais agudas das páginas em branco. Neles se unem, portanto, a infinidade das virtualidades contidas em um livro com a posição acima de tudo ética que precisa emergir do exercício da escrita orientada.

Não esqueçamos: a função-orientador tem relação direta com a aprendizagem investigativa. É, portanto, pedagógica, e carrega consigo a condição de transformação que uma ação dessa natureza enseja. Como nos lembrariam Jan Masschelein e Maarten Simons (2014), nossos aprendizes-investigadores não podem sair os mesmos dos processos de pesquisa nos quais estão envolvidos, e esta mudança tem relação direta com certa apropriação dos sentidos da produção investigativa.

A esse respeito, o retorno a Foucault se torna operacional, posto que ele sempre encontrou na escrita a força transformadora da experiência: escritura como "essa coisa qualquer da qual se sai transformado" (FOUCAULT, 2010, p. 289). O exercício escriturário é visto, por Foucault, como um "trabalho de dessubjetivação" (p. 291), e seguir com ele a pensar no esforço analítico que, mediado por essa figura do orientador, culmina na produção de trabalhos de conclusão de curso, dissertações de mestrado e teses de doutoramento pode ser algo bastante profícuo para que encontremos alguns lugares de operação da funçãoorientador.

Em um texto dedicado ao papel da escrita na ascese grega, Foucault nos dá algumas pistas sobre aquilo em que pode se converter a produção de um texto - o que pode, aqui, nos ajudar a pensar em alguns elementos que consideramos caros a um percurso de orientação voltado, sobretudo, à feitura ética do pesquisador por ele mesmo. Foucault (2006) nos lembra que, entre os exercícios sobre si praticados nos 
primeiros séculos, a escrita assume uma função "etopoiética", transformando "verdade em ethos" (p. 147). A escritura, ao menos como pensada no interior dos treinos de si gregos, possibilita a incorporação das mensagens que a relação com o mundo produz: "a escrita", nos lembrará Foucault a partir de sua leitura de Sêneca, "transforma a coisa vista ou ouvida "em forças e em sangue"” (p. 152). Elemento instaurador de si a partir da presença no mundo, portanto.

Foucault é enfático ao apontar que há aí um papel fundamental da introspecção; tal ideia, no entanto, precisa ser pensada no interior da cultura helênica "menos como um deciframento de si por si do que como uma abertura que se dá ao outro sobre si mesmo" (FOUCAULT, 2006, p. 157) - razão pela qual a correspondência e a coletânea de textos lidos e mensagens ouvidas (os hypomnemata) terão muito mais importância aí do que a enunciação dos recônditos de si mesmo comum a uma série de escritas diarísticas.

Eis aí, talvez, um importante lugar de cruzamento entre a escrita de si da qual falam os estudos foucaultianos e o exercício central àquilo que aqui concebemos como função-orientador. Tal como em Ranciére, o fio mínimo da relação orientadora é o texto - neste caso, sobretudo, mas não somente, aquele escrito pelo orientando. Mas a relação com tal textualidade precisa ser alimentada por uma atitude que considera, do lado daquele que escreve, seus (des)encontros com o mundo; condição sine qua non de qualquer pesquisa, bem sabemos. E, por parte daquele que orienta, é preciso reconhecer o caráter de "presença imediata e quase física" do autor que esse tipo de escrita, em construção - do texto e de si carrega. Razão pela qual não podemos abrir mão desse caráter recíproco que aproxima o texto em orientação da carta:

A reciprocidade que a correspondência estabelece não é simplesmente a do conselho e da ajuda; ela é a do olhar e do exame. A carta que, como exercício, trabalha para a subjetivação do discurso verdadeiro, para sua assimilação e elaboração como "bem próprio", constitui também, e ao mesmo tempo, uma objetivação da alma (FOUCAULT, 2005, p. 156).

Duplo percurso nessa relação escritural: da mensagem do mundo a si mesmo, do que transporto hoje como mensagem ao outro. Essa é das maiores responsabilidades que carregamos enquanto orientadores: a de receber as relações entre o mundo e esse que de nós se aproxima encarnadas em uma textualidade própria. O que fazer, então, diante dela? Arriscamos aqui uma resposta: simplesmente permitir e apoiar caminhos para que a escrita continue a funcionar poieticamente no encontro com aquele que escreve. Isso significa, para relembrar a reflexão foucaultiana, ampliar a viabilidade de um processo de escrita no qual se viva o hesitar típico dos caminhos nos quais ainda não se sabe o que pensar; e no qual, também, se possa vislumbrar o caráter "sonhador" desse exercício (FOUCAULT, 2010, p. 290), envolto na atmosfera de transformação presente naquele que escreve em relação com o mundo (que pesquisa). 
Nossa luta talvez seja, portanto, a de apoiar um movimento escriturário que encaminhe o estudante que escreve "para uma extremidade em que lhe seja preciso sempre se contestar" (FOUCAULT, 2009, p. 224). A atitude aqui é, portanto, predominantemente ética, na medida em que se preocupa com a "prática refletida de liberdade" (FOUCAULT, 2006, p. 268) que tenhamos talvez o dever de ajudar a abrir cada vez mais, como orientadores, em nossos estudantes/pesquisadores. Prática que se apoia menos em nossa capacidade de lhes fornecer delimitações prévias de problemas a pesquisar do que na vontade de encontrar com os orientandos, na escrita, alguns pontos a partir dos quais sejam eles obrigados a iniciar um caminho que, pela novidade que imprime, é sem volta. Uma jornada de transformação de si e de nós, que forja efetivamente o caráter educacional de qualquer investigação.

\section{À Guisa de Considerações Finais: constrangimentos institucionais e (des)orientações}

Para abordar outros contornos e colorações que o exercício da função-orientador pode abrir margem em nossa contemporaneidade, pareceu-nos interessante sublinhar algumas experiências modificadoras que devem emergir nas relações de aprendizagens estabelecidas. Para tal propósito, a possibilidade de que o desnivelamento da ordem explicadora possa ser, quem sabe, atenuado pela incorporação de outras dimensões ao fazer docente caracteriza-se como um desafio e, também, um convite. Desafio porquanto estimula um distanciamento daquelas características que remontam à forma escolar de produção de conhecimento (com suas rotinas, liturgias e rituais). Convite porque faculta as condições para que o compromisso ético da escrita de si (e de nós) desponte como aquilo que concorrerá para que orientadores e orientandos saiam transformados desses (des)encontros de formação propiciados por nossas atuações junto aos cursos de graduação e de pós-graduação (mestrado e doutorado).

Para discorrer um pouco mais sobre esses (des)encontros de formação se constitui como fundamental atentar para alguns constrangimentos e interdições institucionais que definem e autorizam o funcionamento da função-orientador. No caso dos cursos de graduação, por suposto, o orientador deve ter se submetido a todas as exigências, controles e protocolos envolvidos no concurso público para poder exercer a profissão docente. $\mathrm{O}$ aluno, por seu turno, necessita ter sido aprovado no ritual de entrada à Universidade, cursar disciplinas obrigatórias e eletivas, se submeter a avaliações, controles de frequência. Ambos devem, ainda, cumprir prazos e, finalmente, defender publicamente o trabalho final.

No que diz respeito aos cursos de pós-graduação (mestrado e de doutorado), juntamente às dimensões sublinhadas anteriormente, o professor concursado para desempenhar suas atividades no ensino superior deve pleitear o seu credenciamento junto ao programa de pós-graduação. Tal pleito será avaliado levando em consideração, principalmente, as contribuições do postulante à linha de pesquisa, em particular, 
e ao programa, como um todo; suas produções científicas nos últimos anos; as interlocuções concretizadas e as novas possibilidades de inserção no campo de pesquisa.

Esses constrangimentos e interdições institucionais foram, de partida, sublinhados para colocar em relevo que, sob hipótese alguma, deve-se compreender o exercício da função-orientador dissociado de todo aquele repertório de rotinas, impedimentos e circunstâncias que o prescrevem, controlam, legitimam, enfim, autorizam ou desautorizam o seu pleno funcionamento. Tais dimensões concorrem para que devamos pensá-lo, por isto mesmo, como integrante de um sistema de ensino orquestrado a partir, e em função, de relações de saber-poder.

O que é afinal um sistema de ensino senão uma ritualização da palavra; senão uma qualificação e uma fixação dos papéis para os sujeitos que falam; senão a constituição de um grupo doutrinário ao menos difuso; senão uma distribuição e uma apropriação do discurso com seus poderes e seus saberes? (FOUCAULT, 1996, p. 44-45).

Entretanto, ao lado desses constrangimentos e interdições, no exercício da função-orientador há a presença de aspectos, acreditamos, tanto ou mais significativos. Algo que se relaciona a determinada, por assim dizer, "ignorância" dos orientadores. Afinal, como foi explorado, inexiste uma forma ou sistema de ensino que de modo litúrgico, "prepare previamente" os professores para o exercício dessa atribuição.

Desse quadro geral, frente a essa "ignorância" dos orientadores, não parece ser nada casual que nas bancas de defesas de monografia, dissertações e teses que temos participado, com uma frequência cada vez maior, expressões como essas tenham conhecido seus lugares de enunciação: "arriscar caminhos"; "testar hipóteses"; "percorrer trilhas"; "surpresas do trabalho de campo"; "imprevistos do percurso" etc.

Em comum, tais expressões sinalizam para outras formas de ensino (e de aprendizagem) que, juntas, podem (ou, arriscamos dizer, devem!) se fazer presentes neste intricado esforço de produção de conhecimento. Por outras palavras, se compartilhamos da certeza de que a educação não se esgota na forma escolar de ensino e aprendizado, o exercício da função-orientador, ainda que contingenciado por toda sorte de relações de saber-poder, apresenta-se como um convite para repensar a ignorância e, assim, talvez, reintroduzi-la como parte importante (ousamos afirmar, indispensável!) para o despontamento de múltiplas escritas de si (e de nós) que impulsionem a emergência de outras possibilidades interpretativas referentes àquilo que orientadores e orientandos podem, ainda, fazer em nossa contemporaneidade.

\section{Referências}

ALVAREZ-URÍA, Fernando; VARELA, Julia. Arqueología de la escuela. Madrid: La Piqueta, 1991. 
BARROSO, João. Cultura, cultura escolar, cultura de escola. Princípios Gerais da Administração Escolar, v. 1, 2012, p. 181-199.

BOTO, Carlota. A liturgia da escola moderna: saberes, valores, atitudes e exemplos. História da Educação, v. 18 , n. 44,2014 p. $99-127$.

DALLABRIDA, Norberto. Nascimento da escolarização moderna: cotejo de duas leituras.. Perspectiva (UFSC), v. 22, 2004, p. 93-110.

DE CERTEAU, Michel de. A Invenção do Cotidiano 1: Artes de Fazer. Petrópolis, RJ: Vozes, 2008.

DE CERTEAU, Michel de. A escrita da História. Rio de Janeiro: Forense Universitária, 1982.

DELEUZE, Gilles; GUATTARI, Felix. O que é a Filosofia? Rio de Janeiro: Editora 34, 1992.

DUSSEL, Inés; CARUSO, Marcelo. A Invenção da Sala de Aula: uma genealogia das formas de ensinar. São Paulo: Moderna, 2003.

FARIA FILHO, Luciano Mendes de; VAGO, Tarcísio Mauro. Histórias de Escolarização: reformas, currículos, disciplinas e práticas. Currículo sem Fronteiras, v.9, n.1, 2009, p. 5-9.

FOUCAULT, Michel. Conversa com Michel Foucault. In: Ditos e escritos VI. Repensar a política, Rio de Janeiro: Forense Universitária, 2010, p. 289-347.

FOUCAULT, Michel. O pensamento do exterior. In: Ditos e escritos III. Estética: literatura e pintura, música e cinema. Rio de Janeiro: Forense Universitária, 2009, p. 219-242.

FOUCAULT, Michel. Segurança, Território, População: curso dado no Collège de France (1977-1978). São Paulo: Martins Fontes, 2008.

FOUCAULT, Michel. A escrita de si. In: FOUCAULT, Michel. Ditos e Escritos V. Ética, Sexualidade, Política. Rio de Janeiro: Forense Universitária, 2006, p. 144-162. 
FOUCAULT, Michel. A Ordem do Discurso. Aula Inaugural no Collége de France, pronunciada em 2 dez. 1970. São Paulo: Edições Loyola, 1996.

FOUCAULT, Michel. O que é um autor?. Lisboa: Passagens, 1992.

JULIA, Dominique. A cultura escolar como objeto histórico. Revista Brasileira de História da Educação, 2001, p. 9-44.

LE BRETON, David. Antropologia do corpo. Petrópolis, RJ: Vozes, 2016.

MASSCHELEIN, Jan; SIMONS, Maarten. Sobre o preço da pesquisa pedagógica. In: A pedagogia, a democracia, a escola. Belo Horizonte: Autêntica, 2014, p. 55-80.

PETITAT, André. Produção da escola/produção da sociedade: análise sóciohistórica de alguns momentos decisivos da evolução escolar no ocidente. Porto Alegre: Artes Médicas, 1994.

RANCIÈRE, Jacques. O mestre ignorante: cinco lições sobre a emancipação intelectual. Belo Horizonte: Autêntica, 2010.

SCHUELER, Alessandra Frota Martinez. Educar em família: o Colégio Amorim Carvalho na Corte imperial (1882-1889). Revista HISTEDBR On-line, 2007, p. 65-77.

SCHUELER, Alessandra Frota Martinez; SILVA, José Claudio Sooma. Obrigatoriedade Escolar e Educação da Infância no Rio de Janeiro no Século XIX. In: VIDAL, Diana Gonçalves; SÁ, Elisabeth Figueiredo de; SILVA, Vera Lucia Gaspar. (Orgs.). Obrigatoriedade Escolar no Brasil. Cuiabá: EdUFMT, 2013, p. 243-57.

VIDAL, Diana Gonçalves; SÁ, Elisabeth Figueiredo de; SILVA, Vera Lucia Gaspar. (Org.). Obrigatoriedade Escolar no Brasil. Cuiabá: EdUFMT, 2013.

VILLELA, Heloísa de Oliveira Santos. O Mestre-Escola e a Professora. In: LOPES, Eliane Marta Teixeira; FARIA FILHO, Luciano Mendes de; VEIGA, Cynthia Greive. 500 anos de Educação no Brasil. Belo Horizonte: Autêntica, 2007, p. 95-134. 
VINCENT, Guy; LAHIRE, Bernard; THIN, Daniel. Sobre a história e a teoria da forma escolar. Educação em Revista. Belo Horizonte, jun., 2001, p. 7-48.

Recebido em: 18/05/2020

Aceito em: 11/08/2020

Notas:

i Doutor em Educação. Professor Adjunto da Faculdade de Educação da Universidade Federal do Rio de Janeiro, Docente do Programa de Pós-Graduação em Educação (PPGE-UFRJ). E-mail: andreb.ufrj@ gmail.com Rio de Janeiro. ORCID: http://orcid.org/0000-0002-9773-4734

ii Doutor em Educação. Professor Associado da Faculdade de Educação da Universidade Federal do Rio de Janeiro, Docente do Programa de Pós-Graduação em Educação (PPGE-UFRJ). E-mail: claudiosooma@ gmail.com Rio de Janeiro. ORCID: https://orcid.org/0000-0003-3647-8703

iii A comparação, neste ponto, é com todo o conjunto de concursos públicos que exigem dos candidatos a conclusão do ensino superior.

iv Por exemplo, o Programa de Pós-Graduação em Educação da Faculdade de Educação da Universidade de São Paulo (FEUSP).

${ }^{v}$ Embora tenhamos concentrado as atenções na Universidade Federal do Rio de Janeiro, importa destacar que essas atribuições e responsabilidades caracterizam, via de regra, o exercício da carreira docente do ensino superior público no Brasil.

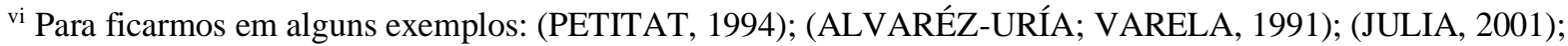

(DALLABRIDA, 2004); (DUSSEL; CARUSO, 2003).

vii Para uma discussão detalhada acerca da emergência do dispositivo da obrigatoriedade escolar e suas diferentes manifestações no Brasil, ver: VIDAL; SÁ; SILVA (Org.), 2013. 